\title{
STUDY OF EXTRACTION CALOPHYLLUM INOPHYLLUM L USING MICROWAVE HYDRODIFFUSION GRAVITY AND CHEMICAL EXTRACTION METHOD
}

\author{
Raka Selaksa Charisma Muchammad I Mahfud Mahfud* I Lailatul Qadariyah
}

Dept. of Chemical Engineering, Institut Teknologi Sepuluh Nopember, Surabaya, Indonesia

\section{Correspondence}

*Mahfud Mahfud, Dept. of Chemical Engineering, Institut Teknologi Sepuluh Nopember, Surabaya, Indonesia. Email: mahfud@chem-eng.its.ac.id

\section{Present Address}

Gedung Teknik Kimia, Kampus ITS Sukolilo, Surabaya 60111, Indonesia

\begin{abstract}
In this study, the oil extraction of Calophyllum inophyllum L using microwave hydro-diffusion gravity method and chemical extraction method were elaborated. The Microwave Hydrodiffusion Gravity (MHG) method is a new green technique which combines microwave-assisted technology and gravitation. It is used to produce oil yield faster and at a low cost. In comparison, a chemical extraction method is a conventional method. The raw material pretreatment, extraction time, microwave power, and the material size have become a crucial factor of extraction. In general, the MHG method yields a higher yield than the chemical extraction method. The MHG method is simple and less solvent. It requires faster extraction time and produces higher oil yield.
\end{abstract}

\section{KEYWORDS:}

Calophyllum Inophyllum L, Chemical Extraction Method, Microwave Hydrodiffusion Gravity Method

\section{1 | INTRODUCTION}

The fossil fuel reserves had been declining in the last decade, growing demand on alternative fuels to substitute fossils fuels. Alternative fuels had been searched in liquid bio-origins this coming from organic material. Organic material proved to be suitable and a good substitution on fossil fuels. The characteristic of organic materials is eco-friendly and renewable.

Calophyllum inophyllum L as known as Nyamplung in Indonesia. Nyamplung is one of the native plants in coastal areas in Indonesia. It has a characteristic of about 8-20 m height with a broad spreading crown of irregular branches ${ }^{11}$. Nyamplung (Calophyllum inophyllum L) often used as ornament or timber for home industry purposes. Calophyllum inophyllum L plant has other uses. Inhibitor cancer drugs because of the xanthones in the stem ${ }^{[2]}$. Then this plant in the world of pharmacy can also be an anti-cancer. Most of the ingredients extracted from Calophyllum inophyllum L plants, 4-phenylcoumarins, are great potential for anti-cancer ${ }^{3}$. Another study of the uses of Calophyllum inophyllum shows Anti-HIV extracted from the leaves of the Calophyllum inophyllum L plant is done by Spino, Dodier, and Sotheeswaran $1998^{[4]}$ showing that the inhibitor activity 
TABLE 1 Composition of composite fatty acids for Calophyllum Inophyllum 1 seed oil.

\begin{tabular}{llc}
\hline Fatty Acid & Category & $\%$ \\
\hline Myristic acid & Saturated fatty acid & $<0,1$ \\
Palmitic acid & Saturated fatty acid & 13,7 \\
Stearic acid & Saturated fatty acid & 14,3 \\
Arachidic acid & Saturated fatty acid & 0,6 \\
Behenic acid & Saturated fatty acid & 0,2 \\
Lignoceric acid & Saturated fatty acid & 0,2 \\
Palmitoleic acid & Unsaturated fatty acid & 0,2 \\
Oleic acid & Unsaturated fatty acid & 39,1 \\
Linoleic acid & Unsaturated fatty acid & 31,1 \\
Linolenic acid & Unsaturated fatty acid & 0,3 \\
Gondoic acid & Unsaturated fatty acid & 0,1 \\
Erucic acid & Unsaturated fatty acid & $<0,1$ \\
Nervonic acid & Unsaturated fatty acid & $<0,1$ \\
\hline
\end{tabular}

against HIV shows good potential as an anti-HIV. In the last decade, it has been found Calophyllum inophyllum L seed can be used as the raw material of liquid bio-oils. Some of the other advantages offered are raw materials because they do not compete with food; these plants can be an alternative in the energy industry. This plant has high fatty acid content, which is then processed into biodiesel with a transesterification mechanism ${ }^{[5]}$. The Calophyllum inophyllum $\mathrm{L}$ plants used for biodiesel produce high yields of Calophyllum inophyllum L oil compared to other types of plants (40-60\% fence distance, 46-54\% oil palm; and 40$73 \%$ Calophyllum inophyllum L). The Calophyllum trees have a high oil yield of 4,560 kg per hectare compared to the yield of 1560 oil per hectare for Jatropha ${ }^{6}$. According to Vian et al. (2008), there is a general composition of Calophyllum inophyllum L oil extracted. Table 1 shows this composition.

In the conventional extraction process of vegetable oils in general, there are many obstacles, such as a lot of impurities and high operational costs. ${ }^{7}$. It is necessary to develop an efficient and capable of Calophyllum inophyllum L seed oil extraction technique to optimize the utilization of Calophyllum inophyllum L plants. The extraction method using the microwave-assisted extraction (MAE) method has been developed and successfully applied using this method is considered to have more value to apply ${ }^{8}$.

Few extraction processes have been developed to obtain bio-oil, such as chemical extraction and mechanical extraction. Chemical Extraction, in general, is oil extraction using a solvent. Pretreatment is required, such as reducing size material and moisture content. The extraction of Calophyllum inophyllum $L$ seed oil uses a solvent to extract the oil from the material. Often high ratio between solvents and material is needed to extract the oil. According to the previous study ratio, 2: 1 between the solvent and the material are favorable. N-Hexane's needs are numerous. Generally, to reduce solvent cost, recovery needs to be done, but the solvents used for extraction can not fully recover. Solvent waste that uses for extraction can be harmful to the environment. The extraction process time is also longer than using mechanical extraction. Oil yield that produced using the chemical extraction method is higher than using automated extraction.

Mechanical extraction is the most conventional among the other methods. In this method, use a manual ram press or screw press tool. Calophyllum inophyllum $\mathrm{L}$ seeds need to be dried before to extract using this method. There were many obstacles to processing seeds using a screw press. The rate of oil production is prolonged. It usually takes several hours to process several samples. The use of this method is very dependent on the design of the tools used for extraction and the inefficient use of vegetable oil extraction ${ }^{9}$. Water content also considers factor to experiment extraction of Calophyllum inophyllum L seeds. It is well known to strong matrix inside seed materials compose of gum, and resin can obstruct the process and gives results lower of oil yield. Microwave heating has different characteristics with conventional heating because heat is generated internally due to the vibrations of the molecules of the material that the microwave wants to heat up. Vegetable oils contain organic compounds that strongly absorb microwave energy. High and low dipolar compounds can be extracted in various compositions by microwave ${ }^{10]}$. Heating with microwaves has the advantage of heating evenly because it does not transfer heat from the outside but generates heat from inside the material. Heating can also be selective, which means it depends on the dielectric properties of the material. Some research results show that microwave heating in chemical synthesis requires a relatively shorter time than conventional heating 11 . It needed to develop a better eco-friendly extraction process. In the last decade, many researchers use the microwaveassisted method has been shown better results on extraction yield ${ }^{[12}$. The heating process using microwaves has a different characteristic than conventional heating. The heat is generated internally due to the internal vibration molecule of the material. 
The microwave-assisted method has been developed in the last decade. The microwave-assisted method that commonly uses was the microwave hydro-distillation method. The microwave hydro-distillation method uses water as a solvent to extract the essential oil. The microwave-assisted method also developed another technique, such as a solvent-free microwave extraction method. The use of the solvent-free microwave extraction method also using microwaves as an energy source. The difference is in the SFME method from the microwave hydro-distillation method is SFME does not use any additional water or solvent to extract the oil. Besides, the techniques in SFME are based on microwave irradiation, and distillation was done in In atmospheric pressure. The oils that obtained using this method are derived from the evaporation of in-situ water contained in the material cause the oil extraction process does not need to use additional solvents such as the extraction method carried out using the microwave hydro-distillation method [ [13]. The research using this method still has several obstacles, such as extracted oil, which is sensitive to the steam distillation conditions even by using solvents. There are still many oils that are lost, so that it requires a lot of time and excessive energy [14]. Therefore, we need to develop a more environmentally friendly extraction process such as Microwave Hydro-diffusion and Gravity technique.

Previous studies indicate that the use of microwave-assisted method shows promising results. One of the methods is Microwave Hydro-diffusion Gravity (MHG) method. It has some advantages method that can reduce energy consumption and time. It shows that MHG is better than some other methods which use microwaves. It indicates that the MHG has better performance of the yield oil extract ${ }^{[15]}$. The MHG has a relatively simple concept; this method puts material inside extractor without adding solvents then extracted, and oil flows down by gravity. The MHG is a combination of microwave and hydro-diffusion of vegetable oils from within the material with gravity to do the separation. In principle, the hydro-diffusion phenomenon, diffusion occurs outside the plant material and then drops with gravity from the microwave extractor and falls through a hollow at the bottom of the reactor. The cooling system outside the microwave oven cools the extract continuously.

In this study, new and original processes for the extraction of vegetable oils were introduced. The procedures use microwave hydro-diffusion and gravity (MHG) in vegetable oil has characteristics that are not volatile and relatively heavy. Thus extraction using this method is more suitable. The oil will flow down to the container by gravity. This paper aims to study the effect of Calophyllum inophyllum L oil characteristic and yield oil extracted using MHG method and compare to the chemical extraction method.

\section{2 | MATERIAL AND METHOD}

\section{1 | Material}

Calophyllum inophyllum L were collected from bangkalan, madura, Indonesia about $50 \mathrm{~kg}$. The seeds were separated from shell and the fruits were cracked open manually. Calophyllum inophyllum L seed that prepared for extraction process will be undergo pre-treatment process. First the seed cleande and shieve to 1 and $2 \mathrm{~cm}$ material size then the seed will be dried according to variable. For dried material variable the seed is placed in oven at $110^{\circ} \mathrm{C}$ to remove water content inside the seed for 24 hours. Meanwhile for wet material the seed will be extracted withoout furthermore preparation.

\section{2 | Method}

The microwave was used for experiment is Electrolux the EMM2308X model with the following specifications: Maximum power of $800 \mathrm{~W}, 220 \mathrm{~V}$ voltage, $1250 \mathrm{~W}$ power, Magnetron frequency of $2450 \mathrm{MHz}(2.45 \mathrm{GHz})$. First, the material weigh to $100 \mathrm{~g}$ then put in inside reactor and set power and time according variable. Microwave Hydrodiffusion Gravity method do not require any solvent. The extraction used various microwave power (300 to 600W) and times (10 to 20 minutes). The microwave hydrodiffusion gravity equipment setup show at Figure 1. Experiment conduct using chemical extraction method using N-hexane as solvent $500 \mathrm{ml}$. The experiment using $100 \mathrm{~g}$ of wet seed material placed inside soxhlet to extract the oil. Using electric heater as energy source.

The experiment was carried out by considering few variables that took an effect on yield extraction of Calophyllum inophyllum L oil. The effects of considered variables such as, extraction time, microwave power and material size known to affect extraction yield. Calophyllum inophyllum L oils obtained from the extraction results is then tested for quality with several parameters 


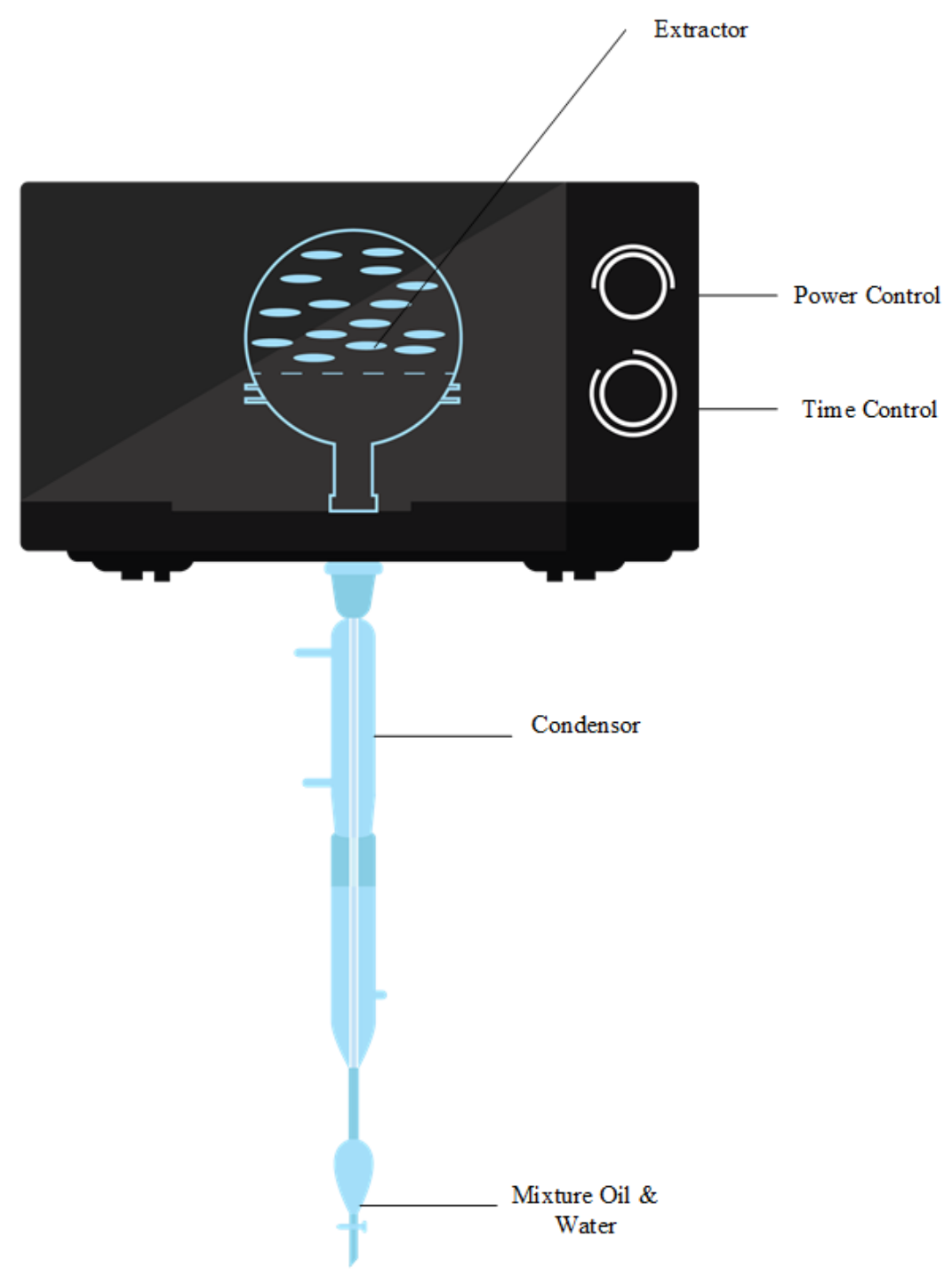

FIGURE 1 Microwave Hydro-diffusion Gravity equipment setup.

such as density, viscosity, acid value. Acid value is a measure of the amount of free fatty acids, and are calculated based on the molecular weight of fatty acids or a mixture of fat. Acid numbers are expressed as the amount of milligrams of $\mathrm{KOH}$ used to neutralize free fatty acids contained in 1 gram of oil or fat.

$$
\begin{gathered}
y i e l d=\frac{o i l \_m a s s}{\text { raw_material_mass }} \times 100 \% \\
\text { water_content }=\frac{\text { wet_mass }- \text { dried_mass }}{\text { wet_mass }} \times 100 \%
\end{gathered}
$$

\section{3 | RESULTS AND DISCUSSION}

\section{1 | Water Content of Material}

The water content of Calophyllum inophyllum $\mathrm{L}$ seed has been measured before experiment conduct. $100 \mathrm{~g}$ of wet seed put inside the electric oven for 24 hours then weigh the mass again after drying. The water content that measured is a mass that calculated 
TABLE 2 Water content results.

\begin{tabular}{lc}
\hline Experiment & Water Content \\
\hline 1 & $18.73 \%$ \\
2 & $19.11 \%$ \\
3 & $18.88 \%$ \\
\hline
\end{tabular}

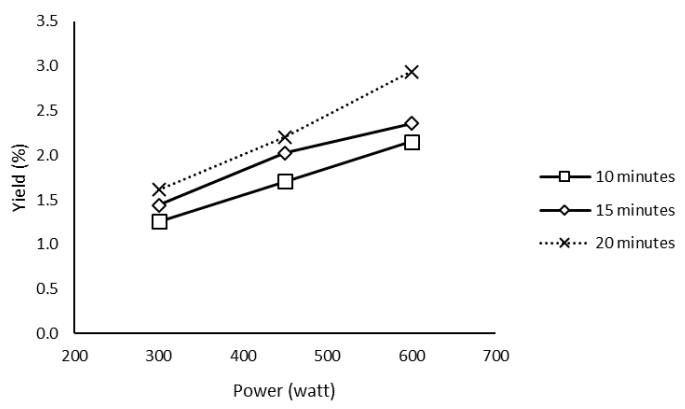

(a)
TABLE 3 Oil extraction parameter result.

\begin{tabular}{lcc}
\hline \multirow{2}{*}{ Paramter } & \multicolumn{2}{c}{ Results } \\
& MHG (dried) & Chemical (wet) \\
\hline Density at 400 C (g/ml) & 0.9125 & 0.9233 \\
Viscosity $(\mathrm{cSt})$ & 52,1334 & 48.5113 \\
Acid Value & 9.5 & 9.7 \\
Color & Dark brown & Yellowish \\
\hline
\end{tabular}

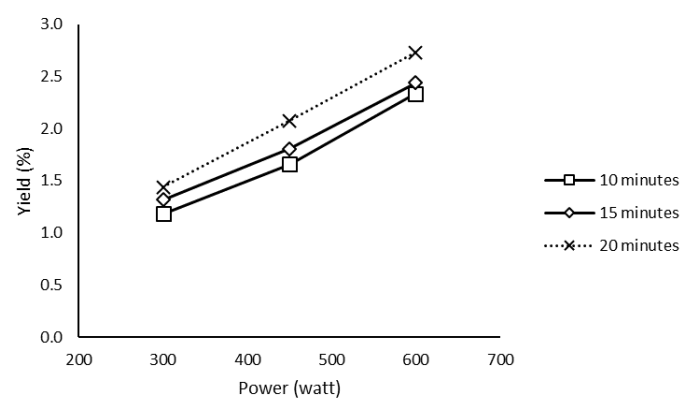

(b)

FIGURE 2 The effect of microwave power on yield dried material of Calophyllum inophyllum L oil using microwave hydro diffusion gravity method size: (a) $\pm 1 \mathrm{~cm}$, (b) $\pm 2 \mathrm{~cm}$.

from material mass after dring compared to before drying. The results of the water content had been shown in Table 2. Water content inside material has different content after drying for 24 hours. Water content that has been removed may improve the oil yield extraction of Calophyllum inophyllum L.

\subsection{The Effect of Microwave Power on Oil Yield}

Power is the amount of energy delivered per unit time (joule/second). The power in the microwave extraction process affects the yield of Calophyllum inophyllum L oil produced through control of the energy supplied into the material and then producing heat energy. This heat energy helps the release of Calophyllum inophyllum L oil along with water from plant material or samples. The higher the power, the effect of microwave vibrations results in increasingly large frequency waves. The speed of movement (vibration) between these molecules then produces a heat The effect so that it influences the process of the release of oil from the material and results in a faster oil flow rate ${ }^{\sqrt{16}}$. Microwave power used in the extraction process using the microwave hydrodiffusion gravity method. Very related to process temperature, where the higher the energy consumed, the process temperature will rise to the boiling point of the polar component in the material. The faster the process temperature increases to the boiling point. The effect of microwave power has been shown in Figure 1

Figure 2 and Figure 3 illustrate the correlation between microwave power used and yield (\%), respectively. The more energy consumed for microwave radiation, the material it also shows on increasing results of yield, the molecules in the material when exposed to microwave radiation, will experience rapid vibrations and collisions resulting in heat energy so that the oil is extracted out along within water inside the material. The lowest results were $300 \mathrm{~W}$ of microwave power on both material size and 10 minute time of extraction give $1,2596 \% 1 \mathrm{~cm}$ size and 1,1817 for $2 \mathrm{~cm}$. The maximum results yield $2.9368 \%$ for $600 \mathrm{~W}$ microwave power at 20 minutes of extraction and $1 \mathrm{~cm}$ material size. This result is not significant. Given $2 \mathrm{~cm}$ material size, the results yield $2.7286 \%$ with $600 \mathrm{~W}$ microwave power at 20 minutes of extraction.

It shows effect microwave power on yield using wet material of Calophyllum inophyllum L oil. It shows maximum operating conditions give maximum yield is $600 \mathrm{~W}$ microwave power at 20 minute time, there is a slight difference of yield at 15 minute time and 20 minutes for $1 \mathrm{~cm}$ and $2 \mathrm{~cm}$ material size. The yield oil extracted for 20 minutes $600 \mathrm{~W} 2 \mathrm{~cm}$ material size is $0.57183 \%$, and for $1 \mathrm{~cm}$, material size is $0.4987 \%$. 


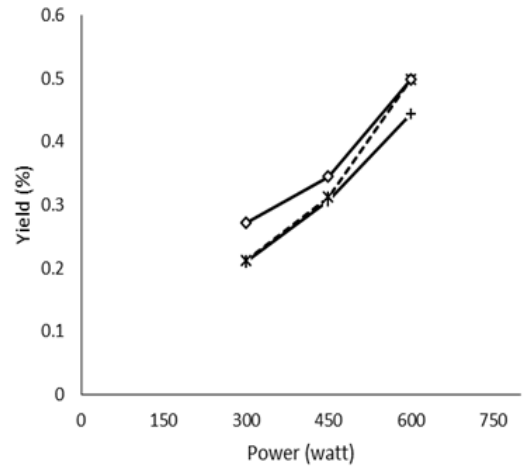

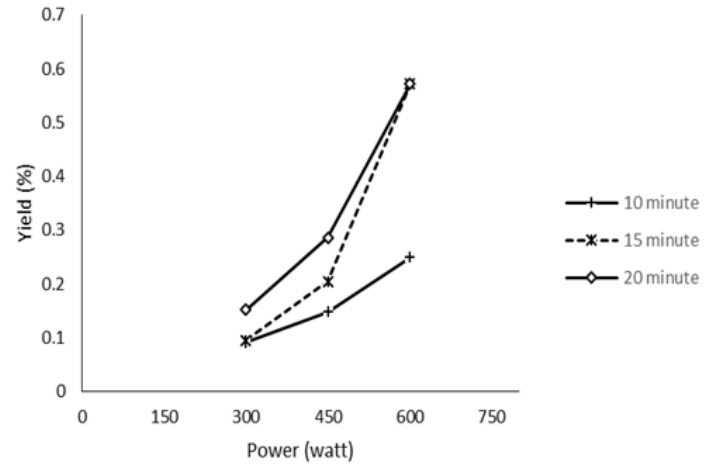

(b)

FIGURE 3 The effect of microwave power on yield wet material of Calophyllum inophyllum L oil using microwave hydro diffusion gravity method size: (a) $\pm 1 \mathrm{~cm}$, (b) $\pm 2 \mathrm{~cm}$.

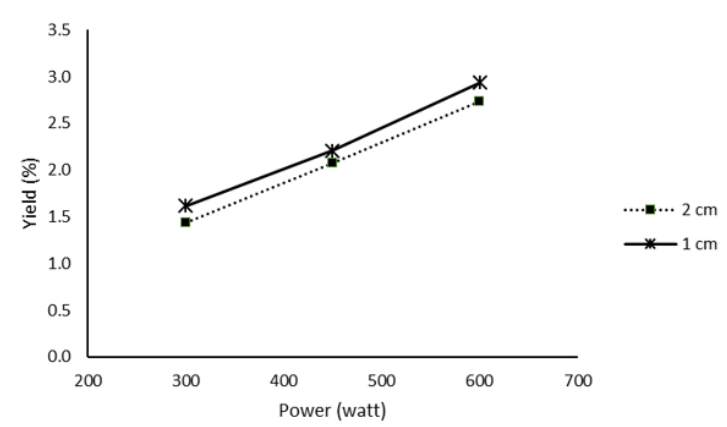

(a)

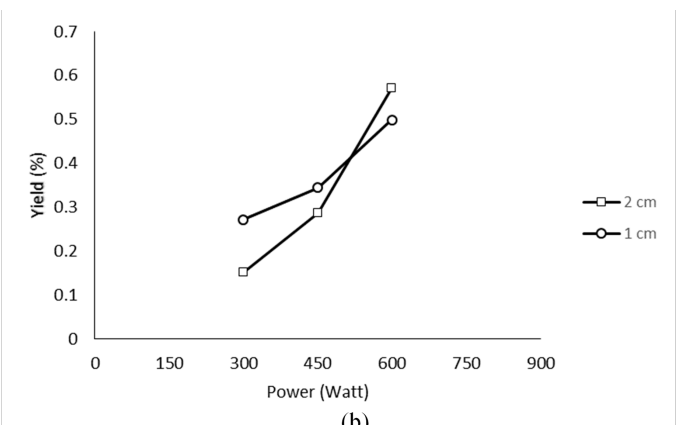

(b)

FIGURE 4 The effect of material size on various power to Oil yield extraction for 20 min: (a) dried material, (b) wet material.

It shows $600 \mathrm{~W}$ of microwave power gives the most maximum results of extraction, increasing in rapid temperature provides a maximum output of yield itself ${ }^{[16]}$. For wet material and dried materials, it shows different results, but in general, along with increasing power of microwave also gives in more increasing yield. The yield oil extraction results show that the dried material gives better results than the wet material. It also shows that in damp material, resin and gum would become an inhibitor of diffusion. They may cause lower yield extraction.

\subsection{The Effect of Material Size on Oil Yield}

Calophyllum inophyllum L seed obtains from Bangkalan, Madura, Indonesia have various sizes to open the kernel must be done using manual labor to keep the volume to a desirable size. Size variance of material that obtains there is a need to uniform the size to observe the effect of material size on oil yield extraction results. Figure 4. illustrates the effect of material size. For dried material, the results of oil yield extraction give maximum results of oil extraction at $1 \mathrm{~cm}$ size, and $2 \mathrm{~cm}$ give the less of oil yield results. But for wet material for 300 to $450 \mathrm{~W}$ microwave power show smaller size give more yield than larger size but at $600 \mathrm{~W}$ maximum yield that obtains $2 \mathrm{~cm}$ material, size has more yield. In general, The smaller size gives more contact with microwave radiation energy. Generally, energy radiation given to material distributes more evenly at $1 \mathrm{~cm}$ material size than $2 \mathrm{~cm}$.

Figure 5 shows the difference between results correlation material size and yield. Material size $1 \mathrm{~cm}$ and $2 \mathrm{~cm}$ for $600 \mathrm{~W}$ microwave power at 10 minute time of extraction, it can generally describe that the yield of Calophyllum inophyllum $\mathrm{L}$ oil using the microwave hydro-diffusion gravity method for $1 \mathrm{~cm}$ compared to $2 \mathrm{~cm}$ with yield maximum operating conditions at $600 \mathrm{~W}$ for 10 minutes. There is a big difference between dried material and wet material in results. For dried material, smaller size produces more yield than the larger size, but for wet material, larger size produces more yield. Wet material contains larger water content 


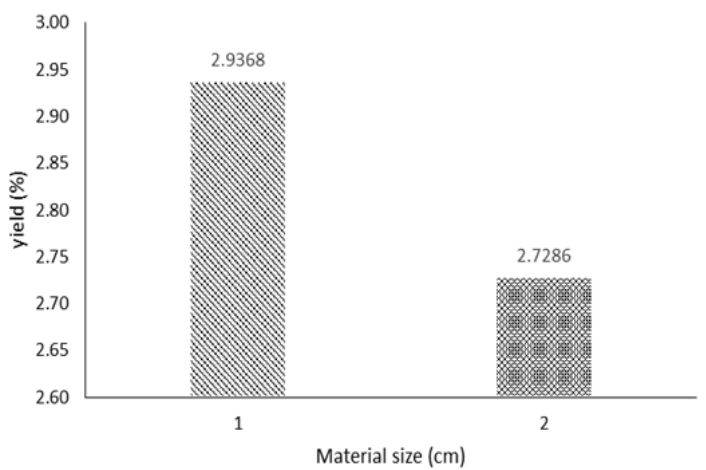

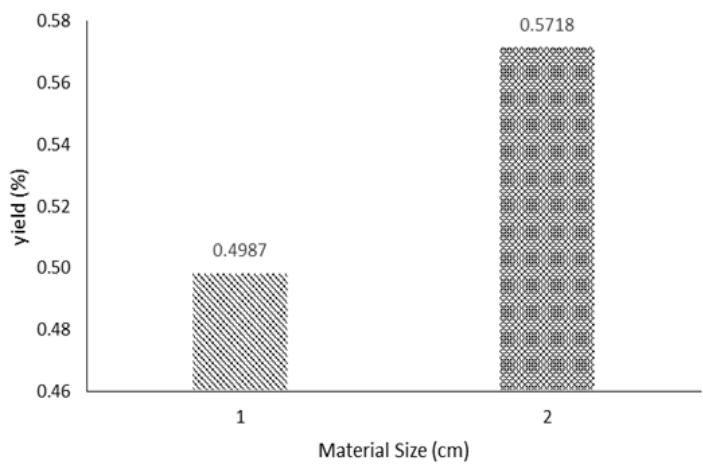

FIGURE 5 Effect of material size on a yield of Calophyllum Inophyllum L oil with microwave hydro diffusion gravity method at the maximum power of $600 \mathrm{~W}$ for 10 minutes: (a) dried material, (b) wet material.

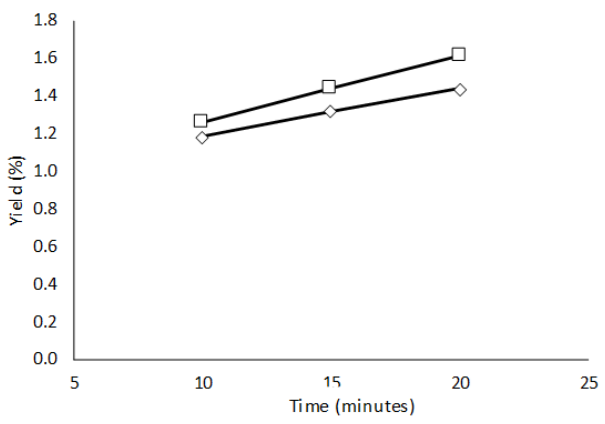

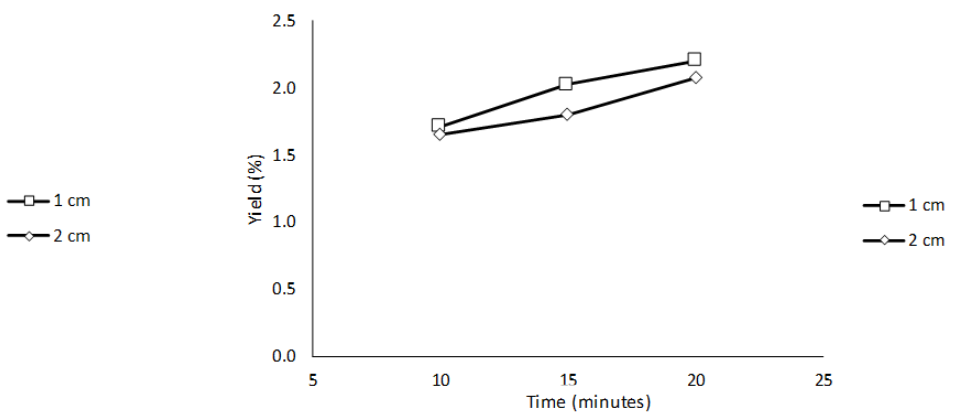

(b)

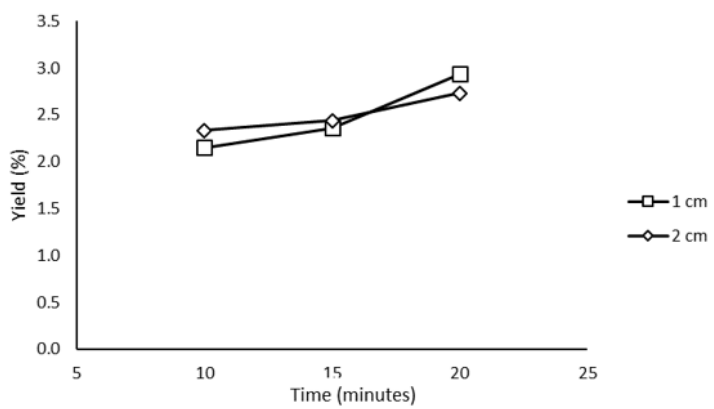

(c)

FIGURE 6 Effect of various extraction time on oil yield: (a) 300W, (b) 450W, (c) 600W microwave power (dried material).

than dried material. It may cause polar molecule inside material to tend easier at a larger scale to vibrate more rapidly when at condition $600 \mathrm{~W}$ microwave power. Figure 4 also indicates that. In general, a smaller size gives a higher yield. It shows that a smaller material size has shown more yield compared to larger size ${ }^{[17]}$.

\subsection{The Effect of Extraction Time to Oil Yield Extraction}

In general, the extraction time effect has three major steps: the equilibrium phase, the transition phase, and the diffusion phase. In the equilibrium phase, there is a transfer of substrate at the material matrix's outer layer. The transfer of the substrate takes place at a constant phase. Then, it is followed by the transition phase itself occur when mass transfer at convection and diffusion step. Lastly, the diffusion step at a slow rate through the diffusion mechanism. In the extraction of Calophyllum inophyllum L oil 


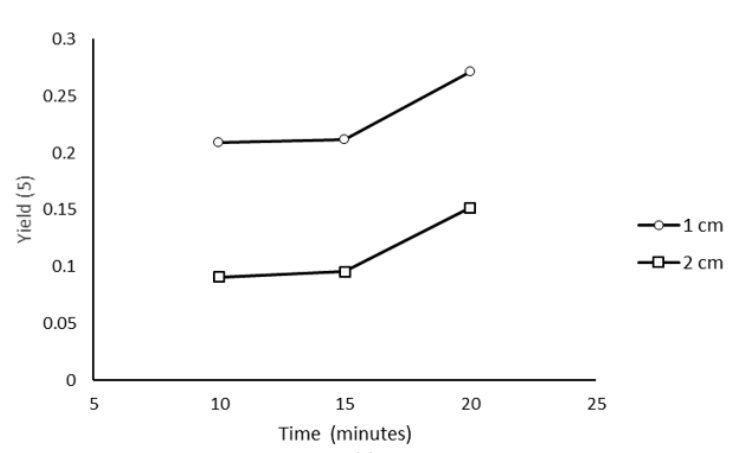

(a)

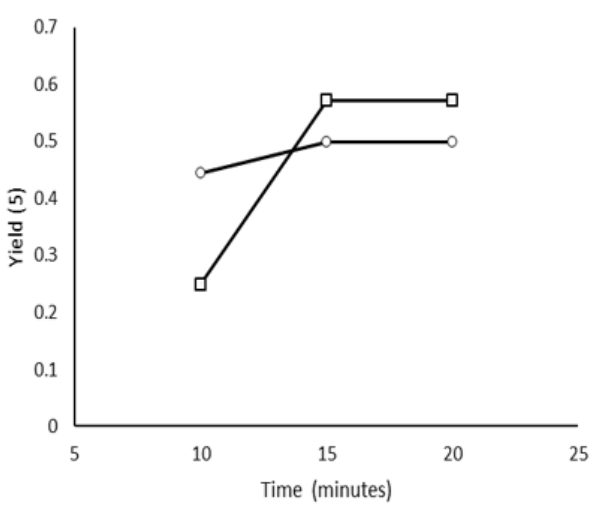

(c)

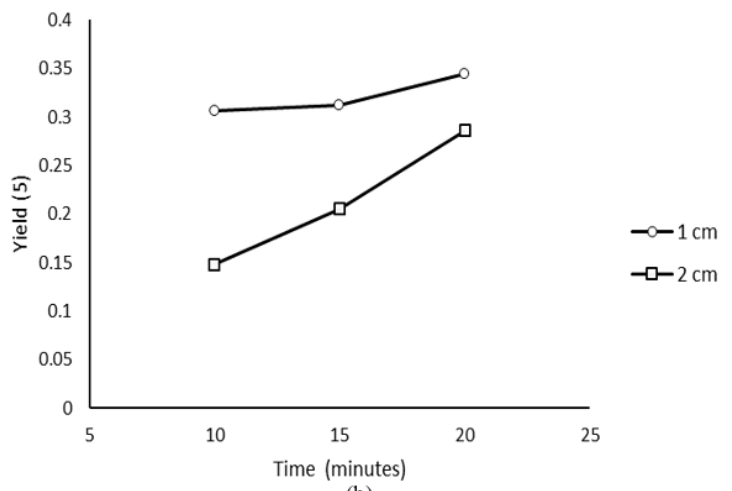

(b)

FIGURE 7 Effect of various extraction time on oil yield: (a) 300W, (b) 450W, (c) 600W microwave power (wet material).

using microwave hydro-diffusion gravity method, extraction time is also one of the critical factors to be considered. In general, the yield that produced will be higher when irradiation time is longer 18.

Figure 6 shows the relation between microwave time and yield using dried material. Microwave time also an essential factor to consider for extraction yield. Figure 6. Every microwave power within 300 to $600 \mathrm{~W}$ shows increasing in results of yield extraction. Figure 6 (a) shows the maximum yield at 20 minutes $1.6153 \%$ for $1 \mathrm{~cm}$ material size. Then Figure 6 (b) maximum yield also obtain at 20 minutes extraction time is $2.2062 \%$. Lastly, figure 6 (c) oil yield maximum extraction is $2.9368 \%$. At for burning phase, the temperature raised rapidly ${ }^{144}$. After more than 20 minutes of the condition of extraction starting to enter the burning phase, it will cause oil will be the color of dark but not reduce the quality of the oil itself. It suggested that vegetable oil consisted of fatty acid.

It illustrates in Figure 7 the relation between microwave time and yield using wet material. Microwave time also an essential factor to consider for extraction yield. Figure 6. Every microwave power within 300 to $600 \mathrm{~W}$ shows increasing in results of yield extraction. Figure 6 (a) shows the maximum yield at 20 minutes $0.2718 \%$ for $1 \mathrm{~cm}$ material size. Then Figure 6 (b) maximum yield also obtain at 20 minute extraction time is $0.3447 \%$. Lastly, figure 6 (c) oil yield maximum extraction is $0.5718 \%$. In general, both Figure 6 and Figure 7 represent the correlation of microwave time and yield, increasing in time also increasing in yield, in Extraction increases the yield along with the time. It also indicates that oil is not fully extracted. During the extraction process, there would be an optimum state of extraction when oil not will no longer be extracted.

\section{5 | Chemical Extraction}

Chemical extraction using a solvent as a medium to extract. In this experiment, using N-Hexane as a solvent. N-hexane Full Merck that used for this experiment. Preparing wet sample material then reducing the size to $2 \mathrm{~cm}$. The experiment was carried 


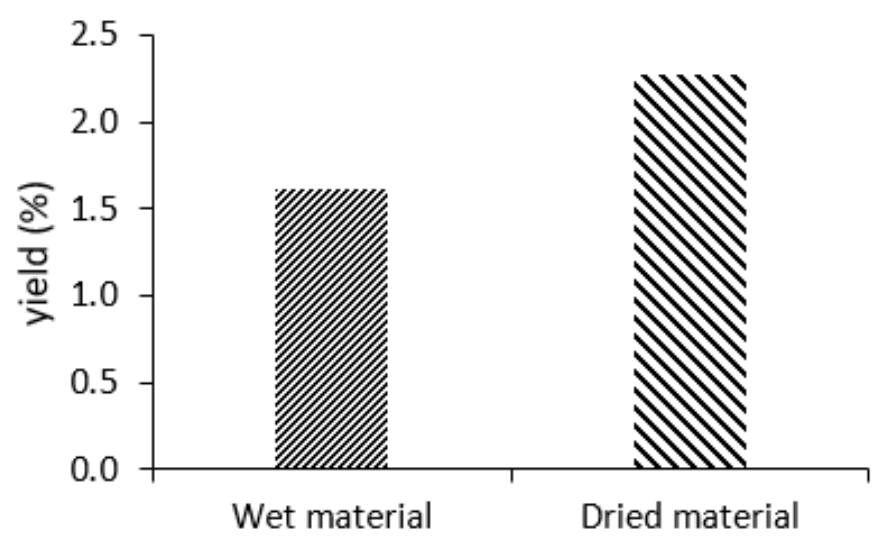

FIGURE 8 Chemical extraction results of dried material and wet material.

out with $100 \mathrm{~g}$ of wet and dried material samples. First, we put the samples inside the soxhlet. Then we added $500 \mathrm{ml}$ of NHexane as a solvent. The experiment was ended when $\mathrm{N}-\mathrm{Hexane}$ color inside soxhlet became transparent. It indicated that there was no longer oil extracted from Calophyllum inophyllum $\mathrm{L}$.

Figure 8 shows the oil extracted from Calophyllum inophyllum L using the chemical extraction method. The experiment was carried out for 6 hours. It shows that dried material gives more yield than wet material. The dried material yield is $2.2789 \%$. According to another study by Arapamarta, et al, 2016. the research conduct using a batch-wise process that needed two solvents to extract oil from the material matrix. N-hexane uses to extract the oil and methanol to extract and separate the resin from the oil ${ }^{[19}$. The yield that was produced using chemical extraction was higher but had several drawbacks. The drawbacks are the need for more costly operations due to the use of chemical solvents, long process of extraction time, and environmental waste due to the use of chemical solvents.

\subsection{Comparison of MHG and Chemical Extraction Method}

In this study, the MHG method was compared to the chemical extraction method. Figure 9 illustrates the comparison between the MHG method and Chemical Method. The MHG method is slightly better than the MHG method. Nevertheless, the results from the MHG and chemical extraction processes indicate that the MHG method is superior at dried material rather than a chemical method producing a higher yield. For wet material that the hexane technique is superior in terms of producing higher oil yields. It was also observed that solvent extraction is more repeatable, both of method has advantages are relative ease of preparation and no requirement for extensive training. However, seed preparation has a significant impact on oil yields, especially using the MHG method. The use of MHG method water content becomes one of obstacle that may cause the producing in oil yield. On the other side MHG and Chemical Extraction using dried material, still producing the highest oil yields. Although the oil extraction technique using the MHG method and wet raw material obtained at a relative fast, this is ineffective due to relatively lower oil yields. The MHG method was relatively expensive at initial capital cost, microwave technology that still developed may be one of many factors.

Moreover, this process is using electrical consumption to operate the microwave. On the other side, the chemical oil extraction technique was found to be one highly effective producing of high oil yield and consistent performance. Still, the lack of a hexane recovery system and a long time in process extraction compared to the MHG method, it was not possible to take full advantage of the effectiveness of the method. MHG process is more simple and faster compared to the chemical method, repeatable and reproducible results. Eventually, Comparing MHG method and chemical method, both method has advantages itself. The MHG method will be more reliable when the preparation of raw material itself has been done correctly. Preparation material will be one of the extra labor time for the MHG method. The MHG method still slightly has better results than the chemical method. 


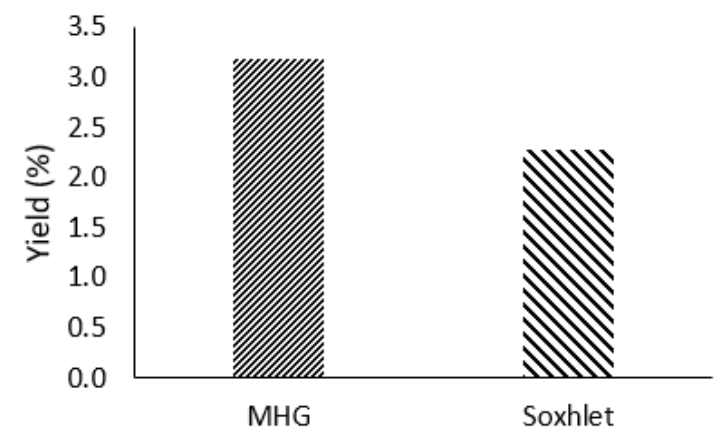

(a)

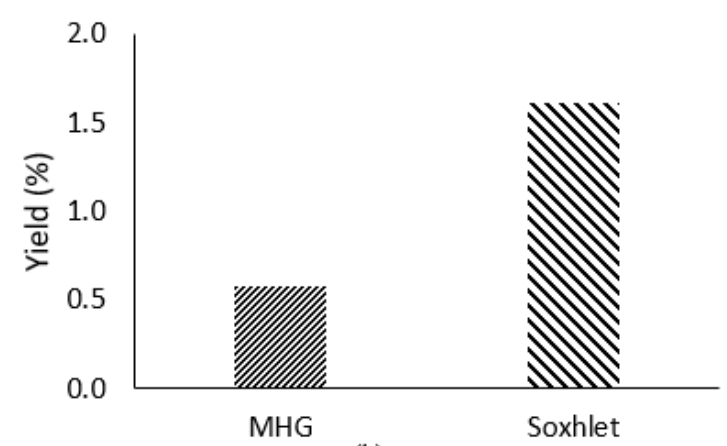

(b)

FIGURE 9 MHG method and Chemical extraction method: (a) dried material,(b) wet material.

\section{7 | Calophyllum inophyllum L Oil Quality assessment}

This experiment has been conducted to assess oil quality that obtains from extraction Calophyllum inophyllum L using the microwave hydro diffusion method. The results of the physical properties oil that obtain shown in Table 3.

The experiment shows that the MHG method results give high viscosity than the chemical extraction method. Matrix inside material compose resin and gum this both material also extracted along with the oil. The high content of gum on oil causes the low quality of physical properties Calophyllum inophyllum L oil due to higher viscosity. On the other, the chemical method gives better viscosity than the MHG method and has more light color due has been separated from resin. MHG yield shows lower results due to the presence of gum, resin, and water content on the material using wet material that needs further preparation to gain higher yield results. Resin and gum were found at cell material to create strong cell-matrix and cause oil challenging to extract, also the presence of water content on material various depend on season and maturity of seed.

\section{4 | CONCLUSION}

This study introduces a new green technology for extracting Calophyllum inophyllum L Oil Q using the Microwave Hydrodiffusion Gravity method. Given the repeatable and reproducible results, we can conclude that the MHG method is simpler and faster compared to the chemical extraction The oils obtained using this method are derived from the evaporation of in-situ water contained in the material cause the oil extraction process does not need to use additional solvents such as the extraction method carried out using the microwave hydro-distillation method. For dried material, the results of oil yield extraction give maximum results of oil extraction at $1 \mathrm{~cm}$ size, and $2 \mathrm{~cm}$ give the less of oil yield results. Material size $1 \mathrm{~cm}$ and $2 \mathrm{~cm}$ for $600 \mathrm{~W}$ microwave power at 10 minute time of extraction, it can generally describe that the yield of Calophyllum inophyllum L oil using the microwave hydro-diffusion gravity method for $1 \mathrm{~cm}$ compared to $2 \mathrm{~cm}$ with yield maximum operating conditions at $600 \mathrm{~W}$ for 10 minutes.

\section{References}

1. Okano JBF, D. Calophyllum Inophyllum (Kamani). Holualoa, Hawai: Permanent Agriculture Resources (PAR); 2006.

2. Mah SH, Ee GCL, Teh SS, Sukari MA. Calophyllum Inophyllum and Calophyllum Soulattri Source of Anti-Proliferative Xanthones and Their Structure-Activity Relationships. Natural Product Research 2015;29(1):98-101.

3. Itoigawa M, Ito C, Tan HTW, Kuchide M, Tokuda H, Nishino H, et al. Cancer Chemopreventive Agents, 4-Phenylcoumarins from Calophyllum Inophyllum. Cancer Letters 2001;169(1):15-19.

4. Spino C, Dodier M, Sotheeswaran S. Anti-HIV Coumarins from Calophyllum Seed Oil. Bioorganic and Medicinal Chemistry Letters 1998;8(24):3475-3478. 
5. Atabani AE, Cesar ADS. Calophyllum Inophyllum L. - A Prospective Non-Edible Biodiesel Feedstock. Study of Biodiesel Production, Properties, Fatty Acid Composition, Blending and Engine Performance. Renewable and Sustainable Energy Reviews 2014;37:644-655.

6. Ashok B, Nanthagopal K, Sakthi Vignesh D. Calophyllum Inophyllum Methyl Ester Biodiesel Blend as an Alternate Fuel for Diesel Engine Applications. Alexandria Engineering Journal 2018;57(3):1239-1247.

7. Jahirul MI, Brown JR, Senadeera W, Ashwath N, Laing C, Leski-Taylor J, et al. Optimisation of Bio-Oil Extraction Process from Beauty Leaf (Calophyllum inophyllum) Oil Seed as a Second Generation Biodiesel Source. In: Procedia Engineering, 5th BSME International Conference on Thermal Engineering, vol. 56 Dhaka, Bangladesh: Elsevier Ltd; 2013. p. 619-624.

8. Arianna Binello, Laura Orio, Giuseppe Pignata, Silvana Nicola, Farid Chemat GC. Effect of Microwaves on the in Situ Hydrodistillation of Four Different Lamiaceae. Comptes Rendus Chimie 2014;17(3):181-186.

9. Bhuiya MMK, Rasul MG, Khan MMK, Ashwath N, Azad AK, Mofijur M. Optimisation of Oil Extraction Process from Australian Native Beauty Leaf Seed (Calophyllum Inophyllum). In: Energy Procedia, The 7th International Conference on Applied Energy (ICAE2015), vol. 75 Abu Dhabi, UAE: Elsevier Ltd; 2015. p. 56-61.

10. Kaufmann B, Christen P. Recent Extraction Techniques for Natural Products: Microwave-Assisted Extraction and Pressurised Solvent Extraction. Phytochemical Analysis 2002;13(2):105-113.

11. Filly A, Fernandez X, Minuti M, Visinoni F, Cravotto G, Chemat F. Solvent-Free Microwave Extraction of Essential oil From Aromatic Herbs: From Laboratory to Pilot and Industrial Scale. Food Chemistry 2014;150:193-198.

12. Nayak B, Dahmoune F, Moussi K, Remini H, Dairi S, Aoun O, et al. Comparison of Microwave, Ultrasound and AcceleratedAssisted Solvent Extraction for Recovery of Polyphenols from Citrus Sinensis Peels. Food Chemistry 2015;187:507-516.

13. Li XJ, Wang W, Luo M, Li CY, Zu YG, Mu PS, et al. Solvent-Free Microwave Extraction of Essential oil from Dryopteris Fragrans and Evaluation of Antioxidant Activity. Food Chemistry 2012;133(2):437-444.

14. Bousbia N, Vian MA, Ferhat MA, Meklati BY, Chemat F. A New Process for Extraction of Essential Oil from Citrus Peels: Microwave Hydrodiffusion and Gravity. Journal of Food Engineering 2009;90(3):409-413.

15. Vian MA, Fernandez X, Visinoni F, Chemat F. Microwave Hydrodiffusion and Gravity, A New Technique for Extraction of Essential Oils. Journal of Chromatography A 2008;1190(1-2):14-17.

16. Kusuma HS, Altway A, Mahfud M. Solvent-Free Microwave Extraction of Essential Oil from Dried Patchouli (Pogostemon cablin Benth) Leaves. Journal of Industrial and Engineering Chemistry 2018;58:343-348.

17. Jahongir H, Miansong Z, Amankeldi I, Yu Z, Changheng L. The Influence of Particle Size on Supercritical Extraction of dog Rose (Rosa canina) Seed Oil. Journal of King Saud University - Engineering Sciences 2019;31(2):140-143.

18. Kartika IA, Cerny M, Vandenbossche V, Rigal L, Sablayrolles C, Vialle C, et al. Direct Calophyllum Oil Extraction and Resin Separation with a Binary Solvent of n-Hexane and Methanol Mixture. Fuel 2018;221:159-164.

19. Aparamarta HW, Saputra T, Claratika A, Ju YH, Gunawan S. Separation and Purification of Triacylglycerols from Nyamplung (Calophyllum inophyllum) Oil by Batchwise Solvent Extraction. Industrial and Engineering Chemistry Research 2016;55(11):3113-3119.

How to cite this article: Muchmammad R.S.C., Mahfud M., Qadariyah L. (2020), Study of Extraction Calophyllum inophyllum L using Microwave Hydrodiffusion Gravity and Chemical Extraction Method, IPTEK The Journal of Technology and Science, 31(1):33-43. 